\title{
A VIVÊNCIA DE MÃES DE BEBÊS COM MALFORMAÇÃO
}

\author{
The experience of mothers of babies with malformation \\ La vivencia de madres de bebés con mala formación
}

Simone Roecker ${ }^{1}$

Lilian Denise Mai

Simone Cristina Baggio ${ }^{3}$

Jocimara Costa Mazzola ${ }^{4}$

Sonia Silva Marcon ${ }^{5}$

\section{RESUMO}

0 objetivo do estudo foi conhecer e compreender a vivência de mães diante do diagnóstico e nascimento de bebês com malformação. Trata-se de uma pesquisa descritivo-exploratória, de natureza qualitativa, desenvolvida em Maringá- PR, com sete mães. Os dados foram coletados em abril de 2009, por meio de entrevista semiestruturada, e analisados mediante a análise de conteúdo. Os dados mostraram que os diferentes momentos do ciclo gravídico-puerperal apresentam fatos e emoções distintos, mas completamente interligados, destacando-se momentos como a constatação da malformação, geralmente durante a gravidez, a sua confirmação ao nascimento e a vivência com o bebê após o nascimento. Conclui-se que a descoberta e confirmação da malformação produz crise e negação das expectativas na mãe e em todos os membros da família, desencadeando mudanças em seu modo de viver; porém, aos poucos, a mãe demonstra superação e aprende maneiras para enfrentar o problema e os preconceitos ligados à malformação.

Palavras-chave: Mães. Gravidez. Período pós-parto. Anormalidades congênitas. Acontecimentos que mudam a vida.

\begin{abstract}
The objective of the present study was to discover and understand the experience of mothers faced with the diagnosis and birth of babies with malformation. It was a descriptive-exploratory qualitative research study, performed with seven mothers in Maringá-PR, Brazil. Data were collected in April 2009 through previously scheduled semi-structured interviews, and analyzed using content analysis. The data showed that the different moments of the pregnancy-puerperium cycle involve various facts and emotions, which are nevertheless interconnected, including confirmation of malformation (usually during pregnancy), confirmed diagnosis at birth, and life with the baby after birth. It is concluded that the discovery and confirmation of malformation leads to crisis and denial of expectations in the mother and all family members, resulting in changes in their way of life. However, the mother gradually overcomes and learns ways to cope with the problem and prejudices associated with malformation.
\end{abstract}

Keywords: Mothers. Pregnancy. Postpartum Period. Congenital Abnormalities. Life Change Events

\section{Resumen}

El presente estudio tuvo como objetivo conocer y comprender la vivencia de madres delante del diagnóstico y nacimiento de bebés con mala formación. Se trata de una investigación descriptiva y exploratoria, de naturaleza cualitativa, desarrollada en Maringá (PR), con siete madres. Los datos fueron recogidos en abril de 2009, por medio de entrevista seme estructurada y analizados mediante el análisis de contenido. Los datos mostraron que los diferentes momentos del ciclo, del embarazo al nacimiento, presentan hechos y emociones distintos, pero, completamente interconectados, destacándose momentos como la constatación de la mala formación, generalmente durante el embarazo, su confirmación al nacimiento y la vivencia con el bebé después del nacimiento. Se concluye que la descubierta y confirmación de la mala formación produce crisis y negación de las expectativas en la madre y en todos los miembros de la familia, desencadenando cambios en su modo de vivir, pero a los pocos la madre demuestra superación y aprende maneras para enfrentar el problema y los prejuicios relacionados a la mala formación.

Palabras clave: Madres. Embarazo. Periodo de Posparto. Anomalías Congénitas. Acontecimientos que Cambian la Vida

\footnotetext{
${ }^{1}$ Enfermeira. Mestre em Enfermagem. Professora do Departamento de Enfermagem do Instituto Federal do Paraná - IFPR. Londrina - PR. Brasil. E-mail: moneroecker@hotmail.com;²Enfermeira. Doutora em Enfermagem. Professora do Departamento de Enfermagem da Universidade Estadual de Maringá UEM. Maringá - PR. Brasil. E-mail: Idmai@uem.br; ${ }^{3}$ Enfermeira. Mestre em Enfermagem. Professora do Departamento de Enfermagem da UNIPAR-PR. Paranavaí - PR. Brasil. E-mail: simone_baggio@hotmail.com; ${ }^{4}$ Enfermeira. Mestranda em Enfermagem pela UEM. Maringá - PR. Brasil. E-mail: jcmazzola2000@yahoo.com.br; ${ }^{5}$ Enfermeira. Doutora em Filosofia da Enfermagem. Professora da graduação e pós-graduação em Enfermagem na UEM. Coordenadora do Núcleo de Estudos, Pesquisa, Assistência e Apoio à Família - NEPAAF. Maringá- PR. Brasil. E-mail: soniasilva.marcon@gmail.com
} 


\section{INTRODUÇÃO}

Em um contexto de debates sobre direitos sexuais e reprodutivos da mulher, um fato que se reveste de importância e gravidade durante o atendimento em seu ciclo gravídicopuerperal é a ocorrência de alguma malformação hereditária ou congênita. A gravidez, por si só, já é um evento de muita significação na vida da mulher e é permeada por valores e transformaç̧ões que se constituem como ímpares. A gestação de um filho envolve diversos sentimentos, tais como alegria, realização pessoal, preocupação, angústia, entre outros, geralmente acompanhados pela idealização de uma criança perfeita.

É comum a construção de um ideal eugenista, centrado no nascimento de uma criança física e mentalmente saudável. Formam-se imagens, sonhos e esperanças ao redor do "ser" que se imagina, ao tempo em que, contraditoriamente, 0 fantasma da malformação assombra durante todo o período gestacional. ${ }^{1}$ A chegada de um bebê com malformação produz descontinuidade relacionada a essa idealização do nascimento perfeito, com sonhos desmoronados e sentimentos negativos, não só para a mãe, mas também para o cônjuge e toda a família ampliada. ${ }^{2}$

Entende-se malformação congênita como uma anomalia estrutural presente ao nascimento, tendo como definição ampla a expressão "defeito congênito", e que inclui toda anomalia funcional ou estrutural do desenvolvimento do feto decorrente de fator originado antes do nascimento, genético, ambiental ou desconhecido. ${ }^{3}$ Segundo dados secundários do DATASUS/ Sinasc, no ano de 2006, nasceram no Paraná um total de 153.598 bebês, sendo que, destes, 1.008 nasceram com anomalias, o que corresponde a 0,65\%. Somam-se ainda os custos psicossociais, como trauma psicológico da família e dificuldades de adaptação à sociedade tida como "normal", inclusive com eminente risco de desestruturação familiar. ${ }^{4}$

Dessa forma, os dados estatísticos em relação à gestação e nascimento de bebês com malformação nos fazem enxergar que a assistência pré-natal dispensada nos serviços de saúde não garante um cuidado integral, humanizado e despido de preconceitos. Portanto, para adentrar nessa vivência complexa, em que as gestantes e a equipe convivem com as dificuldades que permeiam tal situação, torna-se necessário conhecer como se dá a interação entre a gestante/parturiente/ puérpera e a equipe multidisciplinar nos serviços de saúde.

Estudos mostram que o nascimento de um filho que requer cuidados específicos leva a mãe a inserir-se em uma "nova realidade": a representação de que seu bebê é uma criança que apresenta uma série de agravos à saúde, os quais podem se traduzir em sério risco de vida, ${ }^{5}$ e fatalmente as anomalias congênitas sinalizam uma importante causa de óbito no período neonatal. ${ }^{6}$ Ao mesmo tempo, o indivíduo portador de malformação na sociedade moderna ainda é alvo de pessimismo e preconceito, despertando sentimentos de estranheza, impotência e frustração, tanto na população em geral quanto nos próprios profissionais de saúde.?

Um estudo realizado com mães de filhos portadores de síndrome de Down ${ }^{8}$ mostrou que o diagnóstico foi informado em condições e momentos inapropriados, levando os autores a ressaltarem a necessidade de uma atuação diferenciada dos profissionais de saúde junto a estas famílias. Os profissionais precisam, de um lado, ajudar as famílias a reconhecerem suas forças e potencialidades, bem como suas fragilidades e necessidades; e de outro, ao reconhecerem o importante papel da família para essas crianças, precisam efetivamente estar junto com as famílias, apoiando-as e instrumentalizando-as, para que possam, respeitando seus limites e dificuldades, cuidar de seu membro familiar da melhor maneira possível. ${ }^{8}$

Isso, segundo as autoras, significa fornecer informações de forma gradativa e constante, até que a família esteja suficientemente esclarecida e pronta para ajudar o filho. Ressaltam ainda que a família não deve ser "enganada", e, por isso, à medida que as demandas chegam, as informaç̧ões não devem ser omitidas, mas é preciso respeitar o ritmo, a individualidade e o tempo de cada família, já que ela normalmente não está preparada para saber tudo de uma só vez. $^{8}$

Assim, desvelar o que realmente acontece na assistência às gestantes/parturientes/puérperas nesse contexto não é uma tarefa fácil. Uma das principais dificuldades se deve à carência de literatura específica referente ao tema malformação entre os membros das equipes de saúde e entre as mães de bebês com malformações. Acredita-se que a mulher e seus familiares, ao vivenciarem tal situação, sentem muitas dúvidas, medos, incertezas e expectativas. Nesse instante, é preciso sentir-se cuidado, respeitado, amparado e apoiado, papel este que deve ser assumido pelos profissionais de saúde em todos os momentos da assistência seja ela no pré-natal, parto ou puerpério.

Desta forma, a ideia de desenvolver o presente estudo originou-se a partir das discussões teóricas em uma disciplina do curso de Mestrado em Enfermagem, em que emergiram conhecimentos e vivências de enfermeiras quanto ao preconceito e discriminação que sofrem os indivíduos e suas famílias na presença de alguma malformação. Por outro lado, ficou evidente que estas enfermeiras enfrentam dificuldades de atuar como profissionais em relação ao cuidado/assistência dispensados a mães e seus bebês com malformação, situação não incomum no cotidiano de trabalho dos profissionais de saúde.

Diante do exposto, definimos como objetivo deste estudo: conhecer e compreender a vivência de mães diante do diagnóstico e nascimento de bebês com malformação.

\section{MATERIAL E MÉTODO}

Com uma abordagem qualitativa, este estudo caracteriza-se como sendo do tipo descritivo-exploratório, por entender-se que os próprios sujeitos são fonte importante para 
a coleta de informações e dados que possam subsidiar determinadas práticas de cuidado. Nesta modalidade de estudo, os pesquisadores "coletam descrições detalhadas de variáveis existentes e usam os dados para justificar e avaliar condições e práticas correntes ou fazer planos mais inteligentes para melhorar as práticas de atenção à saúde"":111 A pesquisa exploratória caracteriza-se pela busca de uma aproximação sobre o tema já disponível, sobre o assunto a ser abordado, sendo a pesquisa descritiva utilizada para descrever as características de uma população, fato ou fenômeno, por meio de um levantamento das características conhecidas. ${ }^{9}$

A identificação dos bebês foi realizada no Serviço de Epidemiologia da Secretaria Municipal de Saúde (SMS), no município de Maringá, mediante consulta às fichas de inclusão no Programa de Vigilância do Recém-nascido de risco, visto que a presença de alguma anomalia constituiu um dos critérios estabelecidos pelo município para a inclusão no programa.

Este levantamento foi realizado de forma retrospectiva no mês de março de 2009, ocasião em que foram avaliadas as fichas dos bebês nascidos no período de novembro de 2008 a fevereiro de 2009. 0 recorte de tempo justifica-se porque, à medida que as fichas foram sendo levantadas, constatou-se que em quatro meses já haviam surgido os tipos de anomalias mais frequentemente identificadas no projeto "Condições de vida e saúde dos bebês de risco e suas mães, em Maringá/PR, ao longo do primeiro ano de vida", o qual acompanhou durante doze meses o crescimento e o desenvolvimento de todos os bebês nascidos no ano de 2008 no município e incluídos no Programa de Vigilância do Recém-nascido de risco.

Assim, optou-se por encerrar o levantamento neste ponto, tendo sido identificados nove recém-nascidos com malformações. No entanto, duas das nove mães não puderam ser incluídas no estudo, uma por não residir em Maringá e outra por não ter sido localizada. Os informantes, portanto, foram sete mães de crianças portadoras de malformação congênita nascidas no período de novembro a fevereiro de 2009.

0 contato inicial com as mães para solicitação de participação no estudo só foi realizado depois de transcorridos pelo menos dois meses do nascimento da criança, garantindo assim que a abordagem ocorresse em um momento em que a mãe e a família, supostamente, já estivessem lidando melhor com a condição de seu filho. Os dados, por sua vez, foram coletados no mês de abril de 2009, no domicílio das mães, mediante agendamento prévio, por meio de entrevista. Após consentimento, as entrevistas foram gravadas e transcritas na íntegra. Cada entrevista teve uma duração média de 40 minutos.

0 instrumento utilizado durante a entrevista foi um roteiro semiestruturado com perguntas relacionadas à experiência durante a gravidez (cuidados de saúde, prénatal, exames, sentimentos/expectativas, conduta gregária, conhecimento prévio das condições do bebê, condições de saúde materna etc); no nascimento e no período de hospitalização (o parto, conhecimento das condições do bebê, quem estava lá, quem informou, sentimentos/ expectativas, acompanhantes/familiares, amamentação, condições do bebê, tempo de hospitalização, custos, tratamento etc) e após a saída do hospital até o momento da entrevista (tratamento, cuidados, instituições de saúde, amamentação, custos, sentimentos/expectativas, familiares).

A análise dos dados obedeceu a abordagem qualitativa, que pode ser entendida como um "conjunto de técnicas de análise das comunicações, visando obter, por procedimentos sistemáticos e objetivos de descrição do conteúdo das mensagens, indicadores que permitam a inferência de conhecimentos relativos às condições de produção/recepção destas mensagens". 10:44 A análise de conteúdo procura conhecer aquilo que está por trás das palavras sobre as quais se debruça, propondo as seguintes fases: pré-análise; exploração do material; tratamento dos dados com a sua organização sistemática em unidades temáticas; a construção de inferências e a interpretação das categorias significativas. ${ }^{11}$

0 estudo foi desenvolvido em conformidade com 0 preconizado pela Resolução 196/96 do Conselho Nacional de Saúde. Cabe destacar que este estudo é parte integrante de um projeto de pesquisa mais amplo financiado pelo CNPq, denominado "Condições de vida e saúde dos bebês de risco e suas mães, em Maringá/PR, ao longo do primeiro ano de vida", o qual já havia sido aprovado pelo Comitê Permanente de Ética em Pesquisas Envolvendo Seres Humanos da Universidade Estadual de Maringá - UEM (parecer $n^{\circ} 451 / 2008$ ). Todas as participantes assinaram o Termo de Consentimento Livre e Esclarecido (TCLE) em duas vias. Como forma de garantir o anonimato, os extratos dos depoimentos estão identificados com a letra $M$ de mãe e um número que indica a ordem das entrevistas.

\section{RESULTADOS E DISCUSSÃO}

De acordo com o levantamento realizado junto ao Serviço de Epidemiologia da SMS do município de Maringá, no período em estudo (novembro de 2008 a fevereiro de 2009), ocorreram no município 1.433 nascimentos e nove casos de malformação, perfazendo uma proporção de 0,63\% de malformações entre os nascidos vivos. Este índice aproxima-se do que foi encontrado para o estado do Paraná no ano de 2006, que foi de $0,65 \%$.

No Quadro 1 são apresentadas algumas características das mães em estudo, tipo de formação apresentada pelo RN e a época em que foi descoberta; constata-se que apenas dois casos foram descobertos na hora do nascimento e um imediatamente antes do nascimento. Este último foi o caso mais grave, e que resultou na morte do bebê logo após o nascimento. 
Vivência de mães de bebês com malformação

Quadro 1. Características das mães, tipo de malformação do RN e época do diagnóstico. Maringá - PR, 2009.

\begin{tabular}{|c|c|l|c|c|c|c|l|l|}
\hline Mães & Idade & \multicolumn{1}{|c|}{ Ocupação } & $\begin{array}{c}\text { No de } \\
\text { Filhos }\end{array}$ & $\begin{array}{c}\text { Estado } \\
\text { Civil }\end{array}$ & Escolaridade* & Renda & $\begin{array}{c}\text { Malformação } \\
\text { do RN }\end{array}$ & Época da descoberta \\
\hline M1 & 28 & Zeladora & 3 & Casada & EMC & $1.200,00$ & Pé torto & Ao nascer \\
\hline M2 & 40 & Farmacêutica & 2 & Casada & ESC & $4.000,00$ & Síndrome de Down & $3^{\circ}$ mês de gestação \\
\hline M3 & 26 & Bancária & 1 & Casada & ESC & $1.500,00$ & Sindactilia & Ao nascer \\
\hline M4 & 31 & Costureira & 2 & Casada & EMC & $4.000,00$ & $\begin{array}{l}\text { Malformação em } \\
\text { membros } \\
\text { superiores e danos } \\
\text { neurológicos }\end{array}$ & $3^{\circ}$ mês de gestação \\
\hline M5 & 21 & $\begin{array}{c}\text { Auxiliar } \\
\text { administrativa }\end{array}$ & 1 & Casada & ESI & $1.500,00$ & Gastrosquise & $5^{\circ}$ mês de gestação \\
\hline M6 & 38 & $\begin{array}{l}\text { Sem ocupação } \\
\text { M7 }\end{array}$ & 3 & Solteira & EMC & 600,00 & $\begin{array}{l}\text { Malformações } \\
\text { múltiplas }\end{array}$ & $\begin{array}{l}\text { Imediatamente antes } \\
\text { do nascimento }\end{array}$ \\
\hline
\end{tabular}

* Escolaridade: ESC - Ensino superior completo; ESI - Ensino superior incompleto; EMC - Ensino médio completo.

Considerando os depoimentos das mães sobre a experiência vivida, constatou-se que, na maioria das vezes, a malformação é diagnosticada na gestação, é confirmada com o nascimento e, após a alta hospitalar, é efetivamente vivenciada pela mãe e a família. Isto posto, emergiram três categorias empíricas: "Constatando a malformação", "Confirmando a malformação" e "Vivenciando a malformação".

\section{Constatando a malformação}

Das sete mães entrevistadas, quatro fizeram o pré-natal em Unidades Básicas de Saúde (UBS), ou seja, foram atendidas por serviços públicos de saúde (M1, M5, M6 e M7). Nestes serviços, elas tiveram contato com profissionais da enfermagem e da medicina, com um encaminhamento para psicólogo que não foi efetivado por impossibilidade da mãe devido ao seu horário de trabalho. Já as três mulheres que fizeram o pré-natal no sistema privado tiveram contato apenas com o médico obstetra (M2, M3 e M4).

Das mães entrevistadas, duas relataram que a gravidez veio sem esperar; uma delas salientou não ter havido qualquer planejamento:

Em uma hora que a gente estava numa estrutura não tão boa, mas a gente sabia que a gente ia poder seguir em frente. (M5)

Porém, a gravidez é um fenômeno que ocorre dentro do continuum saúde/doença da mulher, e o receio da ocorrência de uma malformação, embora mais comum nos últimos meses de gravidez, também pode se manifestar logo em seu início. Foi o caso de uma mãe que relatou ter realizado tratamento contra um câncer no ovário esquerdo há mais de seis anos e que na ocasião foi alertada pelo médico que poderia vir a ter bebês com malformação devido à medicação utilizada. Ao descobrir a gravidez atual, essa mãe permaneceu até o sexto mês com medo:
Eu sonhava, tinha aquele pesadelo, acordava, faltava uma perna, era horrivel [...] nesse período eu chorava, chorava demais. (M1)

Foi quando a ultrassonografia afastou a possibilidade de malformação, mas trouxe a novidade da gemelaridade, a qual não diminuiu a inquietação:

Então pra mim foi muita preocupação, mais por causa da saúde delas, porque eu achei que ia ter alguma deficiência, e depois porque eu assustei, por serem duas. Demorou um tempo para eu aceitar que eram duas, daí eu vi que estava perfeita, mas eu tinha assustado porque eram duas bebês. (M1)

Ao nascer, um dos bebês apresentou pé torto congênito, resultante da posição intrauterina. Neste caso, para agravar ainda mais a situação, a mãe permaneceu até o quinto mês gestacional sem atendimento médico, sendo acompanhada pela enfermeira da unidade básica, cujas orientações foram muito valorizadas por ela:

Eu fiquei mais segura né, porque eu perguntava muita coisa para ela, eu falei tudo o que eu tinha passado, ela me acalmou [...] nossa, ela foi enfermeira e psicóloga para mim. Então para mim foi muito bom, eu saía de lá aliviada sabe, tanto é que eu queria continuar com ela, mas não podia por serem gêmeas, eu tinha que ter um médico. (M1)

Mesmo baseando-se eminentemente no encaminhamento para outros serviços e na realização de algumas orientaç̃̃es, o trabalho da enfermeira da unidade básica de saúde representou um significativo apoio emocional, conforme evidenciado no discurso: 
[...] ela explicou, ela até me encaminhou para psicologia, mas não deu pra eu ir por causa do trabalho. Ela falou 'não, pode ficar tranquila, se precisar de psicóloga a gente vai e marca, vai atrás. Se você não se sentir preparada[...]. Ela que eu lembro mais; quanto à equipe, se eu precisasse de um exame, alguma coisa, eles corriam atrás [...] do serviço eu não posso reclamar. (M7)

Essa necessidade por maior atenção e apoio emocional durante a gestação, seja por parte da enfermeira, da psicóloga e também muito esperada do médico, acentua-se quando da constatação da malformação e consequente deflagração de uma série de sentimentos, emoções e medos:

Entrando nos 5 pra 6 meses eu fiquei sabendo; aí, quando eu fiquei sabendo, o mundo caiu, acabou, fui correr atrás de médico, e ver o que podia ser feito [...] (M7)

Passei por um período, vamos dizer de umas duas semanas pelo luto de uma criança normal, uma criança que não teria síndrome[...] é que é difícil falar de uma criança normal porque para mim ela é uma criança normal. (M2)

Essa constatação ocorre geralmente no momento da ultrassonografia, que é considerada "como se fosse uma parteira, mostrando à mãe pela primeira vez seu filho. Este momento pode suscitar trauma e desorganização para mulheres psicologicamente não preparadas ou em casos em que há notícia de malformação ou morte do feto" ${ }^{11: 18}$. Na presente investigação, apenas duas mães tomaram conhecimento da malformação no momento do nascimento (M1 e M3); ambos eram casos ortopédicos menos complexos, um deles relacionado ao posicionamento fetal. Dos demais casos, dois foram aos 3 meses de gestação (M2 e M4), dois no quinto mês (M5 e M7) e um imediatamente antes do nascimento, sobrevindo o óbito do bebê em seguida ao nascimento (M6). Mas, em todos, confirma-se a angústia desse momento, em que é marcante a expressão de luto pela criança normal que não viria, choro, vergonha, culpa, procura por alguma causa ou explicação, medo do próprio preconceito ou da discriminação das outras pessoas.

Por outro lado, há curiosidade em conhecer o futuro bebê, há busca por conhecimentos e orientações sobre como melhor proceder, como cuidar e garantir a vida do filho depois do nascimento. Existe a preocupação real pela sobrevivência do filho e sua posterior qualidade de vida. Três mães informaram claramente ter buscado informações, apresentando anseios compreensíveis pelo tipo de malformação; por exemplo, as mães dos bebês com síndrome de Down (M2) e hidrocefalia (M7) destacaram a possível natureza física ou mental dos problemas correlatos. M2 ficou satisfeita com as informações obtidas na internet, com familiares, amigos e profissionais de saúde. Já M7 não obteve as respostas desejadas por parte dos profissionais de saúde, apontando para a precariedade e fragilidade das informações fornecidas por estes. M5 por sua vez, manteve-se no limite do que Ihe foi dito pelo médico, um problema de natureza anatômica (gastrosquise), sendo-lhe informado que a criança iria fazer cirurgia logo após o nascimento:

A gente não tinha noção muito do que era; a gente ficou preocupado, mas não tinha tanta noção do que era [...] (M5)

Os dados também apontam para mudanças de comportamento ainda durante a gravidez em prol da saúde do bebê, bem como para a importância de uma rede social próxima da mãe:

Eu fumava muito e bebia muito vinho, bebia cinco litros de vinho no final de semana e daí parei de fumar, parei de beber logo que descobrique estava grávida. [...] eu trabalho em um colégio de irmã. Nossa, as irmãs me apoiaram muito, conversavam, me levavam na salinha, conversavam bastante comigo, as minhas amigas me abraçavam e choravam junto comigo, as professoras todas tentavam me acalmar e me mostrar [...] tanto é que dos alunos eu ganhei tudo das minhas filhas só de lá, sabe o que é tudo, tudo. Eu não precisei comprar nem um algodão, até as crianças do colégio me ajudaram, todos me incentivaram a aceitar as duas e ter uma boa gestação, diziam: "não se preocupe com nada que o resto a gente resolve', foi quando eu dei uma relaxada. (M1)

Essa rede social geralmente envolve o cônjuge, pais, profissionais de saúde, colegas de trabalho, entre outros. Nesse sentido, salienta-se que a presença de um bebê com malformação na família leva todos os seus membros a desenvolverem novas habilidades de cuidado, a fim de atender todas as suas necessidades. Destacam ainda que as mudanças ocorridas na maneira de viver dessas pessoas delineiam caminhos para que a família enfrente e se adapte à nova situação. ${ }^{12}$

\section{Confirmando a malformação}

Durante a evolução da gestação, mesmo após as evidências diagnósticas que apontam a existência de malformação, algumas mães ainda sustentam a esperança de ter ocorrido um erro e o filho nascer perfeito, sendo o nascimento o momento de confrontar essa esperança com as reais condições do recém-nascido. 
Além de o parto representar o primeiro encontro direto com o bebê, também se revelou a tentativa da observação exata do nível de malformação apresentada pelo filho, previamente identificada em exame pré-natal. Percebeu-se, no entanto, que diante da necessidade de cuidados mais espećíficos e imediatos com o bebê por parte da equipe neonatológica, ainda não é nesse exato momento que a mãe alcança a dimensão do problema do filho. Muitas vezes, o bebê é levado à Unidade de Terapia Intensiva Neonatológica (UTIN) ou fica em observação em incubadora em uma semi-UTI. Tais situações comprometem a vivência da mãe com o bebê no período puerperal imediato, que é contemplada na sequência dos dias de internação em que a mãe tem a possibilidade de observar mais minuciosamente as condições de seu filho.

No presente estudo, quase todos os bebês receberam cuidados em UTIN e um foi submetido a tratamento cirúrgico para a correção de gastrosquise no dia seguinte ao nascimento. Esses fatores reiteram a ideia de que quando o recém-nascido requer cuidados em uma UTIN, isto faz com que a mãe se insira em uma realidade diferente. Estes são acontecimentos que geram uma descontinuidade na relação mãe/filho e maior desgaste emocional à mãe, que tem, de certa forma, protelado a confirmação do bebê real, sendo esta a sua grande expectativa em relação ao nascimento:

Nasceu. A primeira coisa que eu queria ver era[...] diziam que a cabeça cresce, que fica enorme; então, o que eu queria ver era isso, por medo, receio[...].(M7)

Eu vi que era, realmente, a mãozinha praticamente eu nem lembro, mais eu vi o pezinho que tava um pouquinho tortinho, mas que se fosse só aquilo ali teria jeito né. (M4)

Quando vi (...), foi um desespero por ver que ela era tão deficiente. (M6)

0 parto é um momento marcante na vida da mulher, caracterizado por rápidas e grandes mudanças físicas, psíquicas e sociais. Em meio a toda essa transformação, existem fatores facilitadores e for talecedores no processo de formação do vínculo mãe/bebê, assim como fatores prejudiciais a essa relação. ${ }^{10} \mathrm{~A}$ chegada de um bebê com malformação congênita produz descontinuidade relacionada à idealização do nascimento perfeito, com sonhos desmoronados e sentimentos negativos, não só para o casal, mas também para a família ampliada. ${ }^{2}$ Os depoimentos abaixo alertam para as dificuldades vividas pelas mães:

Na hora me deu uma coisa, uma vergonha, não sei, sabe, falei: 'ah meu Deus quando eu for embora todo mundo vai ficar perguntando o que é isso'[...]
A gente fala que aceita, mas é mentira, porque a gente não aceita, não (M1);

Fiquei preocupada, triste, medo que ele amanhã ou depois sofresse alguma dificuldade, preconceito [...], meu filho ser diferente, né. (M3)

Eu tava muito preocupada porque eu cheguei lá, ela estava toda [...] tinha uma bola assim na barriga. (M5)

Os sentimentos negativos que surgem com a confirmação da malformação no momento do nascimento podem gerar conflitos para o relacionamento da mãe com o bebê. Um estudo realizado com enfermeiros de uma unidade maternoinfantil de um hospital geral de São Paulo mostra que, na percepção deles, a decepção quanto às características físicas do recém-nascido constitui um dos fatores de risco para o vínculo mãe/bebê prejudicado. ${ }^{13}$

São marcas que geram nos pais, na família e, de um modo muito particular, na mãe; sentimentos de frustração, vergonha, não aceitação, preocupação, desespero e a necessidade de realmente ver, pois foi ela o corpo gerador desta nova vida inicialmente idealizada, transformando-se em uma realidade diferente do imaginado, com alteração de planos e rotinas para atender às necessidades do novo ser.

Além dos cuidados com o bebê, a própria mãe muitas vezes necessita de cuidados específicos. A presença de edema e hipertensão (M1), inflamação da ferida cirúrgica (M4) ou depressão após o óbito do bebê (M6) são alguns exemplos de demandas maternas. As necessidades físicas são mais facilmente atendidas que as emocionais, tão possíveis e presentes durante esse período de hospitalização após o parto, conforme discurso:

Então eu não sabia o que eu ia fazer com aqueles dois bebês que choravam tanto à noite. Quando foi de domingo pra segunda que eu estava já entrando em pânico [...], eu estava em pânico já [...] a minha vontade, a gente não pode estar falando essas coisas, mas a minha vontade de verdade era pegar, largar elas lá e vir embora, te juro por Deus, eu não queria mais elas, eu falei até pra menina que estava no quarto comigo. Acho que foi até ela que contou para a enfermeira, eu falei: eu não quero mais isso, eu vou embora. Porque elas choravam demais, demais, e eu não sabia o que fazer, porque ninguém me falava nada, sabe. Chegava de manhã: "levanta, vamos trocar os lençóis, não sei o quê, e o banho você vai daro banho', então era muito assim. (M1) 
0 sofrimento era tamanho ao ponto de uma mãe se sensibilizar com a dor do bebê real com outras mães em situação de extrema angústia ou desequilíbrio:

Te juro por Deus, se aquela enfermeira não viesse conversar comigo aquela noite, eu até cheguei pra ela e falei assim: Deus que me perdoe, mais eu estou entendendo agora quando uma mãe pega um filho e joga na parede e faz uma besteira, agora eu entendo o que ela sente antes de fazer isto, era o que eu estava sentindo, eu estava desesperada mesmo, se ela não fosse conversar comigo, me aconselhar e me acalmar, eu não ia aguentar. (M1)

Outro exemplo de demanda emocional é que, após o desespero do primeiro impacto ao ver que a filha era tão deficiente, a mãe iniciou e continua a fazer uso de medicação antidepressiva:

Eu fiquei internada por uma semana, e entrei em depressão, estou até hoje com depressão, agora fazendo tratamento e tomando remédio. Já tomei valeriana, mas não adiantou agora tomo fluoxetina. (M6)

Outro aspecto muito importante logo após o nascimento é a amamentação, e o seu significado para a mãe quando da presença de uma malformação. Uma delas enfatizou o esforço dispendido para ter sucesso com a amamentação:

Porque ela não sabia sugar, ela ficou com uma sonda orogástrica, eu tirava meu leite; não foi leite do lactário, tirava do meu leite e dava para ela através da seringa pela sonda durante estes 18 dias. Quando ela completou 35 semanas, ela já estava sugando, aí eu saí do hospital com ela no peito. (M2)

Uma das mães relaciona 0 ato de amamentar ao fato de o filho reagir bem diante do seu quadro:

Ele pegou bem, não precisou de nada. Como ele ficou uma semana internado, eu achei até que ele não ia conseguir pegar, mas pegou bem. Além de eu ficar feliz por ele ter pego, eu notei que estava tudo bem, que ele, como eu posso falar pra você, ele estava reagindo por ele próprio. (M7)

Independente da idade, formação e classe social, percebeu-se que as mães vivenciam sentimentos de frustração e medo, concomitantes ao amor e preocupação com o bem-estar de seus filhos.

\section{Vivenciando a malformação}

A terceira categoria envolve o período após a alta hospitalar até o dia de realização da entrevista. Compreende, portanto, grande parte do puerpério, reconhecido como um momento crítico e de grande labilidade emocional para a mãe. 0 puerpério é o período que, após o parto, o organismo da mulher precisa para retornar ao corpo que tinha antes da gravidez, sendo caracterizado "pelas regressões das modificações locais e sistêmicas que foram provocadas pela gravidez. 0 seu início se dá logo após a expulsão total da placenta e das membranas e tem a duração de cerca de seis semanas". ${ }^{14: 49}$ Nesse período ocorrem mudanças de humor, associadas ao declínio hormonal da progesterona e do estrogênio que, somadas ao nascimento de uma criança diferente daquela idealizada, podem significar fatores prejudiciais à saúde da mãe ou ao relacionamento e vínculo entre mãe/bebê e mãe/ esposo.

0 fato de estar em seu domićlío é tido como algo bastante confortante, a exemplo dos depoimentos:

Olha, eu não senti dor alguma, as nenéns em casa parece que acalmaram mais, a minha pressão estabilizou de novo eu estando em casa. Foi trabalhoso, foi difícil para eu me entender com as duas, mas foi tudo tão tranquilo, parece que em casa eu fiquei melhor. (M1)

Nossa, a sensação foi maravilhosa, é que a gente começou curtir mesmo ela, agora a gente já vê a evolução, o quanto cresceu, o quanto ganhou peso, ela já começa a fazer barulhinho, sorrir, conhece, então[..]. (M5)

Por outro lado, trata-se de um período crítico, pois, além de todos os sentimentos e expectativas que acompanharam as mães e suas famílias desde a gestação até o nascimento e alta hospitalar, emergem outras preocupações que afetam profundamente a vida dos sujeitos, sendo perceptível a mudança no ritmo de vida:

É uma mudança radical na minha vida e do meu esposo. (M3)

Além da mãe, a família sofre grandes transformações que variam conforme o grau da malformação e as características envolvidas, como o fato de ela ser ou não visível, se ameaça ou não a vida da criança e se implica ou não em hospitalização. Constitui, portanto, realidade que influencia diretamente 0 comportamento de todos os membros familiares. M1, por exemplo, referiu incertezas relacionadas à queda do cordão 
umbilical ou cicatrização dos próprios pontos cirúrgicos, enquanto M7 referiu medo de possíveis alterações mais graves como a ocorrência de convulsão:

Nos primeiros dias eu fiquei com medo, bastante medo [...] eu não estou preparada [...] fiquei, assim, apavorada [...], ele (médico) disse que tinha que ficar em cima e que se tivesse convulsão, tinha que trazer no hospital [...] mas depois eu fui sabendo lidar com a situação. (M7)

A necessidade de muitas idas a especialistas, como pediatra, fisioterapeuta, fonoaudiólogo, ortopedista ou a serviços de saúde, como hospital ou mesmo unidade básica de saúde para imunizações, aumenta sobremodo os custos da família, especialmente daquelas que não têm plano de saúde. Em caso de atendimento público, prevalece a dúvida sobre o acesso ao atendimento:

Sabe, é muito difícil você conseguir médico, que nem agora. A cada trinta dias elas têm que consultar, aí eu fico pensando: 'será que a cada trinta dias eu vou ter um médico pra consultar elas?' (M1)

0 modo como ocorre a evolução da amamentação durante o puerpério também representa um aspecto de grande angústia para a mãe:

No caso da amamentação eu fiquei triste, porque o outro filho eu consegui amamentar, mamava bem, mamou bastante; então, eu não consegui amamentar ela, mas não foi minha culpa, é ela que não pegava [...] (M4)

Nestes casos, mais uma vez é observada a presença, embora negada, do sentimento de culpa como um elemento bastante presente em toda a vivência gravídico-puerperal da mulher.

De modo geral, estas mães reagem buscando a causa que provocou a malformação, e assim procuram em si mesmas uma justificativa ou explicação para o aparecimento do problema. Ressalta-se que o que antes era visto como um presente que completaria todos os vazios da vida dos pais surge como uma realidade que, além de não convergir aos sonhos iniciais, renova os traumas e os descontentamentos anteriores, experimentados com a confirmação do diagnóstico da malformação no decorrer da gestação. ${ }^{15}$

Uma das mães destacou-se em meio às demais, no tocante à ênfase do seu discurso sobre o retorno à vida normal:

O sentimento é de medo, apesar de ter muito carinho, estar muito feliz com a nossa realização, um sonho realizado, né. Mas é medo de não conseguir, e achar que a gente nunca mais vai ter a vida normal, nunca mais vai poder colocar uma roupa como colocava, nunca mais vai poder sair, jantar fora, parece que nunca mais vai ter uma vida normal, até tive depressão pós-parto, você acha que sua vida acabou ali. Enão, a vida da gente começa ali, é uma nova etapa. (M3)

Durante as entrevistas, as mães salientam que as mudanças ocorridas na maneira de viver destas famílias delineiam caminhos para que elas possam enfrentar e se adaptar à nova situação. A interação da mãe com o filho ocorre em mão dupla, pois ao mesmo tempo em que ambos se dão, também recebem, crescem e amadurecem juntos. Neste sentido, ser mãe de um filho com malformação pode tornar-se uma experiência enriquecedora. ${ }^{16}$

0 pós-parto, especialmente após a alta hospitalar, pode ser considerado um período de adaptação, no qual se inicia a aceitação gradativa do filho real, em que a mãe e a família buscam pontos positivos no convívio com uma criança especial, apesar das preocupações quanto ao desenvolvimento deste filho ou a aceitação dele perante a família e a sociedade. Alguns depoimentos exemplificam isso:

Eu saio, mas como ela está com meinha eu não fico mostrando para os outros, o povo é muito curioso, eu nem falo que uma delas tem probleminha na perninha. (M1)

[...] eu não comento muito porque [...] justamente falar de filho seu machuca. (M7)

O convívio social énormal, todo mundo convive com ela, como se fosse uma criança normal, não tem nenhum preconceito e nenhum tipo de exclusão, pelo contrário, ela está incluída tanto na família como no convívio social normal. (M2)

0 diagnóstico de uma malformação, geralmente realizado no período gestacional, é algo muito marcante e causa grandes desordens no núcleo familiar. Mas, quanto mais precoce o diagnóstico, maiores as condições para que a família se reestruture para atender às demandas sobrevindas, buscando uma melhor compreensão sobre a doença que acomete o filho esperado e, ainda, trabalhando os conteúdos emocionais que emergem neste momento. ${ }^{16}$

Ressaltamos que não é somente durante a gestação que a mãe e seus familiares enfrentam e lidam com essa situação, pois, após o nascimento as dificuldades tendem a ser atribuídas às questões sociais, ou seja, a aceitação e convivência com o bebê com malformação.

Estudos mostram que cotidianamente nos confrontamos com o preconceito da sociedade em geral, fato que dificulta, de 
certa forma, a aceitação e a convivência da família com o bebê malformado; ou seja, "o convívio com a diferença ainda não chegou ao nível de naturalidade que muitos esperam, mas as últimas décadas trouxeram uma reviravolta na maneira de ver e compreender as deficiências". 17:79-80 Desse modo, acreditamos que existe grande evolução no que concerne ao modo de ver e agir das pessoas perante as malformações, mas este tema ainda necessita de muita discussão e estudos que auxiliem a sociedade de forma global, mas, em especial, as famílias que convivem com a doença e os profissionais de saúde, a entender e a conviver com bebês com malformações.

\section{CONSIDERAÇÕES FINAIS}

0 estudo permitiu evidenciar que os sentimentos vivenciados pela mãe nos diferentes períodos da gestação é muito peculiar a cada uma, porém, de modo geral percebe-se que indistintamente de faixa etária, condição social ou cultural, as mães expressam sentimentos idênticos no momento que tomam conhecimento da malformação do filho esperado. Um momento crítico na fase pré-natal é a realização da primeira ultrassonografia, exame revelador da presença de algum problema. Isso porque a constatação da malformação produz crise e negação das expectativas, gerando a necessidade de adaptação do filho idealizado para o real, processo que demanda tempo e ocorre de forma conflituosa pela mãe e família durante todo o transcorrer da gestação.

Após esse período pré-natal, o parto representa a confirmação do diagnóstico, em que, além do atendimento às necessidades físicas tanto da mãe quanto do bebê, emerge a necessidade de um cuidado emocional diferenciado para as mães de bebês com malformação. Seguindo-se a isso, a mãe passa efetivamente a vivenciar a presença da malformação no filho e a conviver com ela e todas as suas demandas no período subsequente à alta hospitalar, fase em que se ampliam as possibilidades e necessidades de apoio e orientações de toda a rede social disponível.

Reconhece-se que o estudo possui algumas limitações, destacando-se duas em particular: a necessidade de estender o período da coleta de dados, de modo a ampliar o escopo dos sujeitos e, consequentemente, dos próprios dados e suas possíveis variações; e de eleger novos enfoques sobre a temática, como as implicações da vivência das mães para a assistência prestada a elas e seus bebês nos diferentes momentos do ciclo gravídico-puerperal ou as demandas assistenciais de caráter multiprofissional oriundas do diagnóstico de uma malformação ainda no período gestacional.

Porém, independente disso, convém destacar que os dilemas e contradições que a sociedade vivencia publicamente aparecem no âmbito privado das famílias e, particularmente, das mulheres ao se tornarem mães, como expressão de intensa angústia e dor, em meio ao que deveria representar, e que ainda não deixa de ser, a felicidade do nascimento de um filho.
0 ideal e o esforço eugenista, tanto material quanto emocional, pela perfeição física e mental da descendência, confronta-se com a novidade da malformação e culmina com um difícil processo de aceitação e adaptação às demandas geradas pelas características próprias de cada caso. As mulheres entrevistadas apontam para isso, ao mesmo tempo que revelam a capacidade do ser humano em superar limites e frustrações, construindo e fortalecendo vínculos afetivos que ultrapassam preconceitos e barreiras físicas.

\section{REFERÊNCIAS}

1. Carvalho QCM, Cardoso MVLML, Oliveira MMC, Lúcio IML. Malformação congênita: significado da experiência para os pais. Cienc Cuid Saude. 2006 set-dez.; 5(3): 389-97.

2. Ministério da Saúde (BR). Secretaria de Políticas de Saúde. Área Técnica de Saúde da Mulher. Parto, aborto e puerpério: assistência humanizada à mulher. Brasília (DF):; 2003.

3. Belfort P, Braga A, Freire NS. Malformação arteriovenosa uterina após doença trofoblástica gestacional. Rev Bras Ginecol Obstetr. 2006 fev; 28(2):112-21.

4. Horovitz DDG, Llerena JC, Mattos RA. Birth defects and health strategies in Brazil: in overview. Cad. saude publica, Rio de Janeiro. 2005 Jul/Ago; 21(4):1055-64

5. Rodrigues AS, Jorge MSB, Morais APP. Eu e meu filho hospitalizado: concepção das mãe. Rev. Rene, Fortaleza. 2005 set-dez; 6(3):87-94.

6. Matos LN, Alves EB, Teixeira EMM, Harbache LMA, Griep RH. Mortalidade infantil no município do Rio de Janeiro. Esc Anna Nery. 2007 jun; 11 (2): 283-88.

7. Martins AG, Cardoso MHCA, Llerena Junior JC. Em contato com as doenças genéticas. A norma e a razão como tradições culturais presentes no discurso de profissionais médicos do Instituto Fernandes Figueira, Fundação Oswaldo Cruz, Rio de Janeiro, Brasil. Cad Saude Publica. 2004; 20 (4): 968-75.

8. Sunelaitis RC, Arruda DC, Marcon SS. A repercusão de um diagnóstico de síndrome de Down no cotidiano familiar: perspectiva da mãe. Acta Paul Enferm. 2007 jun; 20 (3) 264-71.

9. Lobiondo-Wood G, Haber J. Pesquisa em enfermagem: métodos, avaliação crítica e utilização. $4^{\mathrm{a}}$ ed. Rio de Janeiro: Guanabara Koogan; 2001.

10. Bardin L. Análise de conteúdo. Lisboa: Ed 70; 2008.

11. Veiga DS. Psicologia da gravidez e parto sob uma ótica psicanalista. Psicópio: rev virtual psicol hospitalar e saude. 2008; 3(6):16-19.

12. Martins DA. Cuidando do portador de síndrome de Down e seu significante. Cienc Cuidad Saude 2002; 1 (1): 117-22. 
Vivência de mães de bebês com malformação

Roecker S, Mai LD, Baggio SC, Mazzola JC, Marcon SS

13. Mendes APD, Galdeano LE. Percepção dos enfermeiros quanto aos fatores de risco para vínculo mãe-bebê prejudicado. Cienc Cuid Saude. 2006 set/dez; 5(3): 363-71.

14. Silva IA, Kimura AF. O período pós-natal: assistência ao binômio mãefilho. In: Ministério da Saúde.(BR) Instituto de Desenvolvimento da Saúde. Universidade de São Paulo. Manual de enfermagem. Brasilia(DF): IDS/ USP/MS; 2001. p. 49-51.

15. Carmignani MCS. Viver ao lado da deficiência mental: a história oral de pais

com filhos deficientes mentais. São Paulo: Vetor; 2005.

16. Gutfreind C. Vida e arte: a expressão humana na saúde mental. São Paulo: Casa do Psicólogo; 2005.

17. Boff J, Caregnato RAC. História oral de mulheres com filhos portadores de Síndrome de Down. Texto \& Contexto Enferm. 2008 set; 17(3): 57886. 